\title{
Dos Montes à vila: \\ considerações em torno da vila medieval portuguesa de Aldeia \\ Galega da Merceana \\ Toponímia, Povoamento, Administração
}

Inês Sofia Lourenço Olaia

Resumo: Pretendemos esclarecer neste artigo as circunstâncias que explicam a evolução do topónimo "Aldeia Galega", localidade atualmente situada no Concelho de Alenquer. Para isso, analisaremos brevemente o povoamento da região e a sua evolução no tempo para justificaras mutações das designações a ela associadas, do composto "Montes de Alenquer", que designou originalmente um espaço mais vasto, até ao "Aldeia Galega da Merceana" com que é conhecida nos nossos dias. O nossoexame centrar-se-á no momento em que todas estas alterações se detetam sucessivamente: da Idade Média aos alvores da modernidade, no período compreendido entre 1220 e 1537 . Da mesma forma, abordaremos as diferenças entre a documentação produzida localmente e aquela que é produzida pelas chancelarias régias, na tentativa de compreender as razões que justificam o apêndice "da Merceana" e a forma como ele é, ou não, absorvido pelos habitantes do lugar.

Palavras-chave: Aldeia Galega da Merceana, Montes de Alenquer, toponímia, povoamento rural, toponímia rural

Abstract: In this paper we aim to clarify the circumstances which explain the evolution of the toponym "AldeiaGalega", a village nowadays located in the Municipality of Alenquer. For that purpose, we will analyze the region's settlement process and evolution in time, to justify the mutations of the designations associated with it, from the compound name "Montes de Alenquer", which originally designates a broader area, to "Aldeia Galega da Merceana", as it is known nowadays. Our exam will focus on the moment when all these changes are successively detected: from the Middle Ages to the beginning of modernity, in the period comprehended between 1220 and 1537. In the same way, we will approach the differences between the documentation produced locally and the one produced by the king's chancellery, in the attempt to understand the reasons that justify the appendix "da Merceana" and the way that it is, or is not, absorbed by the inhabitants.

Keywords: Aldeia Galega da Merceana, Montes de Alenquer, toponimy, rural settlement, rural toponimy

Revista Vernáculo n. ${ }^{\circ} 43$ - primeiro semestre/2019

ISSN 2317-4021 
Todos os que em Portugal atravessam hoje o Alto Concelho de Alenquer, na região Oeste, a norte de Lisboa, pela N115-1, no sentido de Sobral de Monte Agraço, cruzam uma localidade que protagoniza uma situação tão curiosa quanto discreta: Aldeia Galega, sede da freguesia de Aldeia Galega da Merceana ${ }^{1}$. Não é comum que o nome da freguesia difira do nome com que a sua sede se identifica e o que podia ser apenas uma curiosidade tem raízes mais profundas. São os factos históricos que estão na base dessa diferença que nos propomos estudar.

Para executar a análise a que nos propomos foi preciso, antes de mais, reunir, tanto quanto possível, um conjunto sistemático de documentação referente ao lugar e que permitisse sequenciar no tempo as designações que o identificam. No entanto, para justificar a evolução do topónimo, precisámos de aceder a outro tipo de fontes, como a fotografia, e a outros campos historiográficos. Breves incursões pela história institucional do lugar e o seu urbanismo serão necessárias. Uma vez que o nosso estudo se centra na Idade Média, estimamos as balizas temporais entre 1220, quando surgem as primeiras referências, e o ano de 1537, em que o uso do topónimo sofre a última mutação. Mas para compreender a evolução toponímica da área, é importante compreender igualmente a evolução do seu povoamento, por um lado, e o desenvolvimento da sua estruturaadministrativa, por outro. Como

${ }^{1}$ Depois da última reforma administrativa, reunida com a freguesia de Aldeia Gavinha. 
veremos, o primeiro permite o surgimento da situação que analisamos, e o segundo dita a sua alteração e circunstância final.

Este pode ser um estudo valioso para compreender a circunstância de um lugar e de um povoado. No entanto, pode ser um pouco mais que isso: cremos que será um caso de estudo que pode lançar luz sobre as particularidades da organização administrativa do território português na Idade Média. Como veremos, este não é um caso típico ao nível da toponímia ou do povoamento. A essa estranheza junta-se a forma como a evolução da sua estrutura administrativa se encontra registada na documentação: é ímpar no contexto português. Permite-nos lançar mais perguntas do que respostas, é certo. Mas lança, indiscutivelmente, alguma luz sobre um período e uma temática que será sempre tão apetecível quanto obscura, pela escassez de fontes para a maioria dos casos: como surgiram, afinal, os municípios portugueses? O caso que aqui apresentamos não permite generalizações, mas permite compreender, pelo menos, um modo de evolução.

\section{No princípio: espaço, toponímia e povoamento}

Situamos as origens do problema em causa numa situação, por si só, pouco frequente: a coexistência de dois topónimos nos alvores da fundação do reino, um que designa a localidade e outro a região em que a primeira se insere. Assim, para percebermos as razões da discrepância localidade-freguesia que assinalámos, recuamos tanto quanto possível até às primeiras referências documentais ao sítio que pretendemos 
analisar: um rol de Igrejas de padroado régio de 1220-1229, onde surge Santa Maria de Aldeia Galega ${ }^{2}$.A referência atesta a existência de um lugar de dimensão que justifique a ocorrência de uma unidade eclesiástica. O facto não seria surpreendente se não encontrássemos outro topónimo no mesmo local: Monte, ou Montes de Alenquer. Contemporâneo deste rol de Igrejas, o acordo entre as infantas Sancha, Teresa e Branca e o rei D. Sancho II, em 1223, apresenta tanto quanto sabemos, a primeira identificação dessa área como Monte de Alenquer. ${ }^{3} \mathrm{~A}$ coexistência dos dois topónimos é atestada por documentação variada, que teremos oportunidade de analisar, parecendo Aldeia Galega cabeça da região ${ }^{4}$.

A coexistência das duas designações é tão original que se prestou desde cedo a confusões.Localizamos em trabalho do século XVIII ${ }^{5}$ a

${ }^{2}$ Transcritoem BOISSELLIER, Stéphane. La Construction administrative d'un royaume: registres de bénefices ecclésiastiques portugais: XIII-XIVe siècles. Lisboa: Universidade Católica Portuguesa, Centro de Estudos de História Religiosa, 2012 ${ }^{3}$ Vide MORUJÃO, Maria do Rosário Barbosa. Um mosteiro cisterciense feminino: Santa Maria de Celas (século XIII a XV). Coimbra: Biblioteca Geral da Universidade de Coimbra, 2001. p. 242 (doc. 80a).

${ }^{4}$ Vide a título de exemplo, o doc. n. ${ }^{\circ} 141$ do Apêndice documental em RÊPAS, Luís Miguel. Quando a Nobreza Traja de Branco - a comunidade cisterciense de Arouca durante o abadessado de D. Luca Rodrigues (1286-1299). Leiria: Magno Edições, 2003. pp. 458-459.

${ }^{5}$ Localizamos a primeira versão desta interpretação em COSTA, António Carvalho da. Capítulo II. Da Villa de Aldea Galega da Merciana. In:__. Corografia Portugueza e Descripçam Topografica do Famoso reyno de Portugal com as notícias das fundaçoens das cidades, villas e Lugares, que contem Varoens ilustres, Genealogias das Familias nobres, fundaçoens de Conventos, Catalogos dos Bispos, antiguidades, maravilhas da natureza, edifícios e outras curiosas obervaçoens. Lisboa: na oficina de Valentim da Costa Deslandes, 1712, pp. 81-82. Tomo Terceiro.

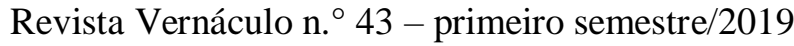

ISSN 2317-4021 
ideia transmitida ao $\mathrm{XIX}^{6}$, de que "Montes de Alenquer" seria o primitivo nome da localidade. O logro mantém-se até ao século $\mathrm{XXI}^{7}$, cristalizado em trabalho escrito e na memória local. E acabamos, assim, por complicar um pouco mais a história desse topónimo: Aldeia Galega inseria-se na região mais vasta dos Montes de Alenquer.

Como acontece frequentemente com a toponímia, detetamos facilmente o sentido prático da designação: é Aldeia Galega o local onde um conjunto de população não nativa se terá instalado a dada altura da história. Não é impossível que esteja relacionado com a existência de outros tantos topónimos semelhantes na zona, o que pode perfeitamente indiciar um conjunto vasto de povoadores que por ali se vai distribuindo, provavelmente chegado do Norte e entrando pela costa até à região de Alenquer, deixando no seu encalço uma pequena

6 Vide BAPTISTA, João Maria. Aldeia Gallega da Merciana. In: Chorographia Moderna do Reino de Portugal, Lisboa: Typographia da Academia Real das Sciencias, 1876. pp. 356-357. Vol. IV. e, para uma interpretação ainda mais fragilizada pelas incongruências noutros detalhes, LEAL, Pinho. Aldeia Gallega da Merciana. Portugal Antigo e Moderno. Lisboa: Livraria Editora de Mattos Moderira e Companhia, 1873. pp. 82-85. Vol. I Nem o autor que escreveu sobre o concelho de Alenquer escapou ao equívoco: HENRIQUES (da Carnota), Guilherme João Carlos, Alenquer e seu Concelho. Fac-símile da edição de 1873, Arruda dos Vinhos, Arruda Editora, 2005, p. 302.

7 A título de exemplo, veja-se: MELO, António de Oliveira, GUAPO, António Rodrigues e MARTINS, José Eduardo. O Concelho de Alenquer: subsídios para um roteiro de arte e etnografia. [Alenquer]: Câmara Municipal de Alenquer e Associação para o Estudo e Defesa do Património de Alenquer, 2002. p. 33. Vol. 1. É claro de onde vem a associação do topónimo Montes de Alenquer a um hipotético antigo nome de Aldeia Galega: a obra copia o que se diz na Corografia Portugueza, acima mencionada.

Revista Vernáculo n. ${ }^{\circ} 43$ - primeiro semestre/2019

ISSN 2317-4021 
constelação de povoações. ${ }^{8}$ Sustentando esta ideia podemos juntar dois indícios mais: a existência, na zona, de património da catedral de Santiago de Compostela de que não se conhece a origem, mas seguramente anterior ao primeiro quarto do século XIII, e a presença na toponímia de nome próprio semelhante ao de um cónego da referida catedral que viveu em Alenquer por este período. ${ }^{9}$

Talvez possamos ainda dizer que essa situação de povoamento externo estará na origem do Monte de Alenquer como unidade geográfica. Claro que, sobre esta última ideia não temos base de sustentação mais sólida até ao momento, mas é hipótese aliciante e justificável: estabelecida a área onde esses colonos se instalariam, o "Monte de Alenquer", os lugarejos que estes fundam tomam outros nomes e farão parte dessa unidade.Torna-se ainda mais clara a funcionalidade do topónimo e a possibilidade atrás enunciada quando lemos a identificação de dois moradores no lugar de Aldeia Galega

${ }^{8}$ É nesse sentido que aponta SILVA, Manuela Santos. Galegos e Minhotos à conquista do litoral do centro de Portugal. Vestígios da sua presença e acção na região medieval de Óbidos. In: BARROCA, Mário Jorge (coord.). Carlos Alberto Ferreira de Almeida: in memoriam, [Porto], Faculdade de Letras da Universidade do Porto, 1999. pp. 397-408. Vol. II

${ }^{9}$ A documentação que nos permite tirar esta conclusão cita-se no final deste artigo; recolhem-se no Arquivo da Catedral, nas Carpetas de Documentos Sueltos, e no Arquivo da Universidade de Santiago de Compostela várias referências, mas as mais antigas, do início do século XIII e que mencionam estes clérigos, estão no Tumbo B do arquivo catedralício, publicadas em VIANA Y VIEITES, José Inácio Fernández de; GONZÁLEZ BALASCH, María Teresa. Documentos sobre derechos y posesiones de la iglesia compostelana en tierras portuguesas en los tumbos "b" y "c" y en el "tumbillo de concordias" de la Catedral de Santiago. Cuadernos de estudios medievales y ciencias y técnicas historiográficas, Granada, $\mathrm{n}^{\circ} .17$, pp. 359-398, 1992.

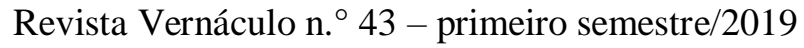

ISSN 2317-4021 
quase dois séculos mais tarde, corria já o século XIV:moravam então na "Aldeia Galega dos Montes de Alenquer"10.

Mas como sabemos que o termo de Alenquer estava em condições de permitir a instalação de colonos e a formação de uma unidade "administrativa" por parte daqueles? Foi já apontado que é provável, embora de difícil comprovação, que o termo de Alenquer se encontrasse muito pouco povoado ao tempo da passagem da vila para mãos cristãs. Contribuíram para essa noção, principalmente, as sucessivas doações feitas a grupos de colonos estrangeiros, circunstância que apontámos, e a extensa doação feita ao mosteiro de Alcobaça, todas ocorridas no século XII ${ }^{11}$; a estas podemos juntar ainda uma propriedade não despicienda desde muito cedo nas mãos de Santa Cruz de Coimbra, a sul de Aldeia Galega, ${ }^{12}$ e outra pertencente a São João de Tarouca. ${ }^{13}$ No

${ }^{10} \mathrm{O}$ documento em causa é uma venda e está datado de 11 de setembro de 1328 , nas casas do mercador envolvido na transação. Arquivo Nacional da Torre do Tombo, Colegiada de Nossa Senhora dos Prazeres de Aldeia Galega da Merceana, n. ${ }^{\circ} 15$ (numeração a azul, Igrejas de Aldeia Galega da Merceana e Reguengo Grande).

${ }^{11}$ Vide FERRO, João Pedro. Alenquer Medieval (séculos XII-XV): subsídios para o seu estudo. Cascais: Patrimonia, 1996. pp. 25-26.

${ }^{12} \mathrm{O}$ conjunto das propriedades do mosteiro no termo de Alenquer está organizado a partir da granja de Palhacana, a sul de Aldeia Galega e descrito em A.N.T.T., Cónegos Regulares de Santo Agostinho, Mosteiro de Santa Cruz de Coimbra, Livro 94, f. 153v, 154. Logo em 1181 detetamos documentação sobre bens na região no fundo do mosteiro: A.N.T.T., Cónegos Regulares de Santo Agostinho, Mosteiro de Santa Cruz de Coimbra, liv. 6, fl. 3.

${ }^{13} \mathrm{O}$ original perdeu-se, mas conservou-se uma cópia transcrita em AZEVEDO, RUI e ALMEIDA, Luís Ferrand de. Documentos Medievais Portugueses. Lisboa: Academia Portuguesa de História, 1941, p. 369. Vol I, tomo 2. A doação foi efetuada por D. Afonso Henriques e data de 1164. Embora não se diga a que termo pertence a propriedade, mais tarde o mosteiro tem problemas com uma património em Palhacana, termo de Alenquer. A.N.T.T., Ordem de Cister, Mosteiro de Santa Maria de Alcobaça, 2. ${ }^{\mathrm{a}}$ incorporação, maço 27, n. $^{\circ} 678$.

Revista Vernáculo n. ${ }^{\circ} 43$ - primeiro semestre/2019

ISSN 2317-4021 
entanto, já em início do século XIII, facilmente detetamos que a rede paroquial do lado oeste do termo de Alenquer está estabelecida: as igrejas de Aldeia Galega, Ventosa e Palhacana são igrejas de padroado régio. ${ }^{14}$ Se estas são resultado desse esforço de povoamento ou de outras circunstâncias é um problema que não temos meios para solidamente resolver. De qualquer forma, a escassez do povoamento, como vimos até aqui e veremos adiante, parece ter permitido não só o estabelecimento de um grupo de colonos como a sua organização numa comunidade estruturada que perdurou.

Sobre a instalação desse grupo no território, quanto aos limites do seu domínio, pouco conseguimos vislumbrar. A imagem que nos fica do período islâmico é difusa: as descrições fornecidas pelos geógrafos árabes deixam no ar a sensação de que a maior parte do espaço rural era desabitada, nas palavras de José Mattoso. ${ }^{15}$ Ainda assim, não podemos ignorar que em torno dos grandes centros urbanos se organizaram, mais que não seja por questões de abastecimento e pela atração exercida por essas cidades, um conjunto de "constelações urbanas". O desenvolvimento destas redes estende-se por todo o período dos primeiros reinados, de Afonso Henriques a D. Dinis. Entre estas constelações, a de Lisboa conta com dois núcleos que dominam as áreas

${ }^{14} \mathrm{Na}$ lista das igrejas de padroado régio de 1220-1229 publicada em BOISSELLIER, Stéphane. La Construction administrative d'un royaume: registres de bénefices ecclésiastiques portugais: XIII-XIVe siècles. Lisboa: Universidade Católica Portuguesa, Centro de Estudos de História Religiosa, 2012. A referência a Santa Maria de Aldeia Galega está na p. 102.

${ }^{15}$ MATTOSO, José. Identificação de um país. Lisboa: Círculo de Leitores, 2015, p. 355.

Revista Vernáculo n. ${ }^{\circ} 43$ - primeiro semestre/2019

ISSN 2317-4021 
a oeste e este de Aldeia Galega: Torres Vedras e Alenquer, respetivamente. A estes, juntamos Arruda dos Vinhos ${ }^{16}$, a sudeste. A área que estudamos e a que se chamará Montes de Alenquer espraiar-seá precisamente no espaço em aberto entre os três. Depois da conquista pelas forças de Afonso Henriques, conseguimos delimitar esse espaço a norte: o senhorio de Vila Verde dos Francos é entregue, como o nome indica, a povoadores francos muito cedo. $\mathrm{Na}$ verdade, sabe-se igualmente que Vila Verde teve foral dado pelo seu senhor através de uma confirmação praticamente contemporânea do foral de Alenquer. ${ }^{17}$ A restante fronteira fica por conta da serra de Montejunto.

Ainda assim, é preciso ter em conta que, naturalmente, este espaço não seria um total vazio: a toponímia, mais uma vez, não só atesta a existência de estruturas militares como as atalaias e as torres, tanto no espaço que delimitámos como fora dele, mas aponta igualmente a existência de uma comunidade cristã não amuralhada e a alguma distância de Alenquer. Tratavam-se dos chamados "moçárabes", ou seja, cristãos aculturados aos costumes e língua árabes e que continuaram a praticar a sua fé sob domínio muçulmano. O lugar chama-se hojeMossorovia e é um pequeno lugarejo da freguesia de

${ }^{16}$ Vide FERRO, João Pedro. op. cit., p. 28: doada a freires de Santiago e já com organização própria em 1189. A doação à Ordem de Santiago, está publicada em AZEVEDO, Rui de, e ALMEIDA, Luís Ferrand de. op. cit., pp. 409-410 e datada de 1172.

${ }^{17}$ Vide FERRO, João Pedro.op. cit., p. 26. A doação a D. Alardo e a outros francos que já continha a obrigação de dar o foral, datada de 1160, está transcrita em AZEVEDO, Rui de, e ALMEIDA, Luís Ferrand de, op. cit., p. 349.

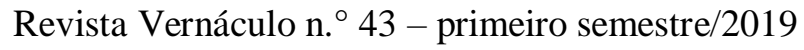

ISSN 2317-4021 
Aldeia Gavinha ${ }^{18}$, que provavelmente viu o seu nome derivar de uma Monçaravia. ${ }^{19}$ Nada se sabe, além do topónimo, sobre a sua vivência.

\section{O nascimento das autoridades e das instituições formais}

Estabelecido o espaço com que trabalhamos, passamos a tentar perceber as estruturas que o organizam internamente. Na segunda metade do século XIII, deparamos com outra realidade interessante, mas que é difícil de discernir em detalhe. Sabemos, desde a década de 1260, de um selo dos "Montes de Alenquer" que acaba por se identificar como estando associado ao juiz. A simples existência do selo atesta a existênciade uma unidade administrativa com algum tipo de autodeterminação e representação naquela região; mas a forma como o mesmo selo é sucessivamente identificado é enigmática. Vejamos: em 1260 o documento menciona apenas o selo dos Montes na roboração, mas o próprio selo define-se como o selo do juiz dos Montes de Alenquer. ${ }^{20} \mathrm{~A}$ designação neste caso parece-nos ambígua. Normalmente, este tipo de selos é legendado com os dizeres "sigillum consillii de ...". No nosso caso, apresenta-se apenas como "S : IVDICIS : MO(n)TIS :

${ }^{18}$ No interior do termo de Aldeia Galega. Atualmente, quem circular entre Torres Vedras e Alenquer pela N9 passará pelas referências ao local, já depois das duas aldeias.

${ }^{19}$ Informação recolhida em OLIVEIRA-LEITÃO, André de. O Povoamento no Baixo Vale do Tejo: entre a territorialização e a militarização (meados do século IX - início do século XIV). 2011. 177 f. Dissertação (Mestrado em História Medieval) Faculdade de Letras, Universidade de Lisboa, Lisboa.

${ }^{20}$ A.N.T.T., Ordem de Cister, Mosteiro de Santa Maria de Celas, maço 9, n. 31. Cumpre-nos agradecer à Prof. Doutora Rosário Morujão a transcrição da legenda e à Mestre Marta Santos as valiosas ideias que partilhámos.

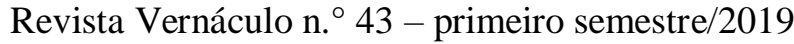

ISSN $2317-4021$ 
DE : A?", o que nos aponta para o juiz e não o concelho. Três décadas depois a documentação identifica expressamente o selo do Concelho dos Montes $^{21}$. E em 1305 ficamos a saber que o Concelho autoriza o juiz a colocar o selo do Concelho na procuração passada aos três indivíduos que negoceiam o acordo inerente ao foral ${ }^{22}$. Nenhum destes últimos selos chegou até nós, nem fisicamente nem através de descrição para que se possa comparar com o exemplar sobrevivente. Ficam por esclarecer os termos desta relação entre o selo, o juiz e o concelho: é o selo do juiz, cuja matriz passará entre todos os que ocupam esse lugar, ou representa todo o Concelho, já que o juiz o encabeça? O Concelho em si tem outra forma de se representar para validar documentação? Se assim é, qual é a relação entre os dois? Sucedem-se no tempo ou coexistem? Em finais do século, dissemos que se apresenta já como "Concelho". Essa unidade administrativa possui, em meados do século XIII uma autoridade tão válida como a da vila de Alenquer: chega a acontecer a documentação surgir validada com os selos de ambos, lado a lado. $^{23}$

Em tudo isto, precisamos ainda de ter em conta a ambiguidade com que o termo "Concelho" nos chega. Pode tratar-se, pelo menos numa fase inicial, de um "Concelho", uma assembleia gerada

${ }^{21} \mathrm{O}$ documento já foi por nós referenciado: vide supra, nota 4.

${ }^{22}$ Todo o processo de concessão do Foral está transcrito em OLivro das Lezírias d'ElRei D. Dinis. Transcrição, Estudo Introdutório e Notas de Bernardo de Sá Nogueira. Lisboa: Centro de História, 2003. pp. 97-101. Na p. 100: "E eu sobredicto juyz per mandado do sobredicto concelho esta procuraçom do seelo do dicto concelho seelej." ${ }^{23}$ Trata-se do mesmo caso que apontávamos na nota $n .^{\circ} 21$. 
organicamente por aquela comunidade (talvez vindo a partir dos povoadores originais daqueles montes?), que teria algum tipo de poder regulado por si própria. O uso da palavra significando assembleia está atestado nos alvores do século XIV em Alenquer. ${ }^{24}$

\section{Um foral original}

O Concelho dos Montes de Alenquer (seja qual for a forma que devamos adotar para o designar), tem, portanto, algum tipo de reconhecimento exterior a si próprio: como dissemos, possuium selo, com que valida documentos que são apresentados a outras entidades. Nomeadamenteao próprio rei: no momento de conceder foral àquela região, não só D. Dinis diz, expressamente, que o faz ao Concelho desses montes ${ }^{25}$, como reconhece a procuração que leva o selo do Concelho e que já referimos ${ }^{26}$. É, da mesma forma, evidente que a autoridade detida pelo Concelho no tempo em que não tinha foral ou

${ }^{24}$ A. N. T. T., Gavetas, Gaveta 15 , maço 22, n. ${ }^{\circ} 22$, copiado em A. N. T.T., Chancelarias, Chancelaria de D. Dinis, Livro 3, fls. 38-39.

${ }^{25}$ A seguir ao protocolo, a seguir ao rei, à rainha e ao herdeiro, diz o documento: "querendo fazer graça e mercee ao Concelho de Montes de Alenquer dou-lhys e outorgo que aiam daquj adeante compridamente pera sempre o foro que hora a vila d'Alanquer". Vide OLivro das Lezírias d'El-Rei D. Dinis. Transcrição, Estudo Introdutório e Notas de Bernardo de Sá Nogueira. Lisboa: Centro de História, 2003, p. 97.

${ }^{26}$ Vide idem, ibidem. O passo que citámos na nota 21 fecha a procuração. Antes de o tabelião trasladar este documento assevera da sua autenticidade, acabando por mencionar a presença do selo. Não há que enganar: "procuraçom seelada com seelo pendente desse concelho", idem, ibidem, p. 98.

Revista Vernáculo n. ${ }^{\circ} 43$ - primeiro semestre/2019

ISSN 2317-4021 
autoridades concedidas pelo rei ${ }^{27}$ já lhe permitia tomar decisões e assumi-las perante os seus pares: uma das justificações para a concessão do foral de 1305 é a fidelidade a Sancho II, tio de D. Dinis. ${ }^{28} \mathrm{~A}$ referência por si só deixa-nos com perguntas por responder. D. Dinis estaria, portanto, a recompensar a fidelidade dos Montes de Alenquer a D. Sancho II, o monarca deposto substituído no trono por Afonso III? Sabemos que as duas vilas de maior dimensão, que eram, na verdade, a última linha de defesa de Lisboa por terra, Alenquer e Torres Vedras, apoiaram abertamente Afonso III após a sua chegada. Sem fortalezas que os defendessem e desconhecendo-se pormenores do conflito na zona, não conseguimos aprofundar em que é que essa fidelidade dos Montes, provavelmente em contracorrente, se teria traduzido, caso se trate de mais que retórica.

A própria concessão do foral compreende, além desta recompensa de fidelidade, a entrega ao rei de uma quantidade monetária não despicienda, se tivermos em consideração que é precisamente esse o valor em que Figanière estima os rendimentos anuais da rainha D. Isabel de Aragão poucos anos depois ${ }^{29}$,e ainda a cedência de um terreno

${ }^{27}$ Este é, de facto, um dos pedidos que fica expresso na procuração indicada. Vide idem, ibidem, p. 99: "e pera auermos tabellion confirmado por el rej e nosso senhor el rej deue meter todalas outras justiças que por bem teuer."

${ }^{28}$ Diz o rei: "E esta graça e esta mercee lhys faço por serviço que mj fezerom e porque eu achei que fezerom lealdade em teer con seu senhor el rey don Sancho". (Vide idem, ibidem, p. 98)

${ }^{29}$ As contas foram feitas por FIGANIÈRE, Frederico Francisco de La. Memorias das Rainhas de Portugal. D. Teresa - Santa Isabel. Lisboa: Typographia Universal, 1859., pp. 179-180, a partir do valor concedido por D. Dinis aos hipotéticos testamenteiros da rainha para a execução das suas vontades, contando os rendimentos das terras que a

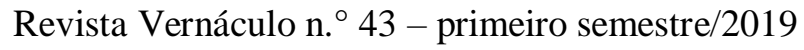

ISSN $2317-4021$ 
conhecido como "Corte dos Cavalos" que gerará conflitos com a vila de Alenquer, por esta considerar que era, na verdade, de sua jurisdição. ${ }^{30} \mathrm{O}$ problema fecha-se com o julgamento à revelia do concelho de Alenquer por parte do ouvidor de D. Dinis: consta que o concelho de Alenquer, já depois do foral dos Montes de Alenquer, o trazia escondida e sonegada ao rei a Corte dos Cavalos. Convocado o procurador, o concelho recusase a avançar na demanda... e o ouvidor julga-o à revelia e manda entregar a propriedade ao almoxarife de D. Dinis. ${ }^{31}$

Só por si, o episódio da concessão do foral abre a porta a uma série de considerações sem paralelo, tanto quanto sabemos, no Portugal Medieval. Não temos notícia de outro caso em que as condições da concessão da carta de foral estejam tão amplamente registradas, por um lado; por outro, tal permite-nos confirmar a pré-existência de um concelho organizado, em paralelo com aquilo que se tinha já intuído para outros casos. Talvez o mais notável seja mesmo a sua manutenção nesta situação não dependente do monarca em sentido direto até tão tarde.

A mesma circunstância, de existência de uma organização anterior ao foral, foi detetada para Torres Vedras, numa fase muito anterior: a vila recebe foral em 1250 de Afonso III, confirmando a

rainha alocava para essa função. Tenha-se em conta que este data de 1314, e os Montes de Alenquer pagam o mesmo valor ao rei em 1305.

${ }^{30}$ A. N. T. T., Chancelarias, Chancelaria de D. Dinis, livro 3, fl. $43 \mathrm{v}$.

${ }^{31}$ A. N. T. T., Chancelarias, Chancelaria de D. Dinis, livro 3, fls. 43v. - 44.

Revista Vernáculo n. ${ }^{\circ} 43$ - primeiro semestre/2019

ISSN 2317-4021 
existência de um concelho. ${ }^{32}$ Duas circunstâncias contribuíram para essa constatação: não só se reconheceram juízes e alcaides (governadores do castelo) em Torres Vedras anteriores ao foral, como este envolve, um pagamento ao rei. É impossível não estabelecermos o paralelo com os Montes de Alenquer. Além disso, socorremo-nos da vila régia mais próxima porque Alenquer não nos ofereceu ainda testemunhos sólidos que nos possam ajudar: só detetámos um pretor (alcaide) em período anterior ao foral. ${ }^{33}$ Por outro lado, Alenquer não é propriamente vila régia durante toda a primeira metade do século XIII: é senhorio das infantas Sancha e Teresa, filhas de Sancho I. A documentação para todo o período escasseia, mas é ainda mais rara para a fase anterior ao foral concedido por Sancha, em 1212.

Precisamos de ter ainda em conta que a concessão destes três forais que aqui referíamos acontece já num momento em que a preocupação essencial não é a fixação de população, como o tinha sido em tempo de Afonso Henriques e Sancho I. Ao tempo de Afonso II,

${ }^{32}$ Uma leitura das primeiras linhas do foral de Torres Vedras facilmente nos faz retirar essa conclusão. Vide VICENTE, António Balcão et. al. O foral Medieval da vila de Torres Vedras. 15 de Agosto de 1250. Torres Vedras: Município de Torres Vedras, 2001. p. 49.

33 A ambiguidade do documento não se presta a conclusões sólidas, mas está relacionado com a instalação de colonos, precisando para esse efeito de ser chamado o pretor de Alenquer à presença do rei em 1199, acompanhado dos oficiais de Lisboa e Santarém. Para perceber a dificuldade, basta comparar o resumo apresentado nos Documentos de D. Sancho I (Vide AZEVEDO, Rui Pinto de; COSTA, Avelino de Jesus da; PEREIRA, Marcelino. Documentos de D. Sancho I. Coimbra: Centro de História da Sociedade e da Cultura da Universidade de Coimbra, 1979. pp. 180-181. Vol. 1) com o apresentado no Livro das Lezírias d'el-Rei D. Dinis (vide OLivro das Lezírias d'El-Rei D. Dinis, Transcrição, Estudo Introdutório e Notas de Bernardo de Sá Nogueira, Lisboa, Centro de História, 2003, p. 144)

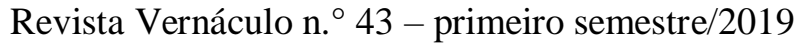

ISSN 2317-4021 
tanto os forais por ele concedidos como pelos que o rodeiam, destinamse maioritariamente a assegurar a lealdade da população, bem como sustentam circunstâncias relacionadas com a circulação de moeda e estabelecem estruturas de apoio social e político ${ }^{34}$, ao encontro de outro tipo de interesses, tanto da parte do rei como dos particulares.

\section{A primeira mudança: do concelho dos Montes à vila de Aldeia}

\section{Galega}

Retomando o nosso estudo concreto em torno de Aldeia Galega, é durante o século XIV que a designação de Montes de Alenquer cai em desuso, ou porque já não era prática, não correspondendo à realidade mental da população, ou porque simplesmente já não fazia sentido aplicá-la desse modo. É através da forma como os tabeliães se identificam que conseguimos percecionar com maior facilidade e precisão a transição. Em $1346^{35}$ o tabelião (que redige e valida as escrituras locais) ainda se diz da vila e dos Montes. O documento é singular por se tratar do único caso em que tal oficial faz questão de assinalar os dois topónimos e de os dissociar claramente. Essa necessidade pode evidenciar a queda iminente do segundo. Uma mão cheia de anos depois, perdemos a designação dos Montes de Alenquer,

${ }^{34}$ SILVA, David Fernandes, "O foral como texto jurídico", NUNES, Graça Soares e SILVA, Paulo (coord.). 800 anos do foral 1212-2012. Vila Franca de Xira: Museu Municipal, Câmara Municipal de Vila Franca de Xira, 2012. p. 45.

${ }^{35}$ A 20 de janeiro de 1346, em Aldeia Galega diz o tabelião: "Em presença de mijẹm martim anes tabeliom do dicto logo e dos montes dalanquer". A.N.T.T., Ordem de Cister, Mosteiro de Santa Maria de Alcobaça, 2. ${ }^{a}$ Incorporação, Maço 56, n. ${ }^{\circ} 11$.

Revista Vernáculo n. ${ }^{\circ} 43$ - primeiro semestre/2019

ISSN 2317-4021 
e o tabelião já se apresenta apenas como sendo de Aldeia Galega. ${ }^{36} \mathrm{O}$ que é que justifica esta alteração, não sabemos dizer ao certo. Pode, na verdade, ter a ver com a alteração do oficial, que opta por se apresentar de forma diferente, e estar minada pela escassez documental. Não podemos, no entanto, ignorar que é expressão de uma alteração neste contexto; tanto mais que não voltamos a recuperar o topónimo. $\mathrm{Na}$ década seguinte, o tabelião apresenta-se como sendo do rei no "lugar"37.

De tudo o que dissemos atrás pode ter resultado, por outro lado, a aparente divisão e difusão do termo da vila de Aldeia Galega nas centúrias seguintes e já palpável no problema da cedência da Corte dos Cavalos ao rei. No momento em que o em que se redige a contagem populacional de 1527, o termo da vila de Aldeia Galegatem várias localidades repartidas com o termo da vila de Alenquer. ${ }^{38}$ Ao tentar traçar os limites do termo em léguas a partir dos dados desse documento, deparamos inclusive com dois problemas: o notário não o faz no sentido de Alenquer, aparentemente confuso com a distribuição

${ }^{36}$ A.N.T.T., Ordem de Cister, Mosteiro de Santa Maria de Alcobaça, 2. ${ }^{a}$ incorporação, maço 50, n. ${ }^{\circ} 1362$. O tabelião diz-se" d'el-Rei em Aldeia Galega".

${ }^{37}$ Em 1356, já o tabelião se diz de Aldeia Galega (A.N.T.T., Colegiada de São Pedro de Torres Vedras, maço 1, n. ${ }^{\circ}$ 64). Ainda assim, salientamos que a 21 de novembro de 1363, em Aldeia Galega, o tabelião já se identifica como o tabelião do rei no lugar. O dizer-se do rei é uma novidade e não é impossível que essa alteração, depois desta data sistematizada, tenha peso na queda do topónimo "Montes de Alenquer". A.N.T.T., Colegiada de Nossa Senhora dos Prazeres de Aldeia Galega da Merceana, n. ${ }^{\circ} 18$ (numeração a azul, Igrejas de Aldeia Galega da Merceana e Reguengo Grande). ${ }^{38}$ Publicada a porção que nos interessa em FREIRE, Anselmo Braamcap. Povoação da Estremadura no XVI século. Archivo Historico Portuguez, Lisboa, Vol. nº 6 , n. ${ }^{\circ}$ 7, pp. 241-284, 1908. O documento resulta do primeiro censo que se pretendia generalizado da população portuguesa, mandado fazer por D. João III. A historiografia consagrou chamar-lhe Numeramento de 1527 , ano em que se iniciou a contagem de população.

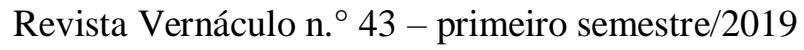

ISSN 2317-4021 
dos lugares do termo desta vila dentro do de Aldeia Galega; por outro lado, frequentemente o termo de Aldeia Galega se cruza com a área que se identifica nesse mesmo documento como sendo termo de Alenquer. Seriam, de facto, espaços extraordinariamente imbricados e em que o uso quotidiano provavelmente definia as jurisdições.

\section{Uma (in)dependência e a construção dos lugares físicos do poder}

Haverá algum outro fundamento para perceber este desaparecimento da designação "Montes de Alenquer"? Talvez dois indícios senos apresentem. Em 1346, Aldeia Galega parece ter ainda algum tipo de dependência face a Alenquer: embora o juiz colocado pela infanta D. Constança ${ }^{39}$ se apresente como sendo do lugar, é possível que haja sobreposição com o seu homólogo de Alenquer. Pode tratar-se de simples homonímia, mas o facto é que o juiz desta vila tem exatamente o mesmo nome que o de Aldeia Galega. ${ }^{40}$ Poderia igualmente tratar-se apenas de um caso específico, em que o problema resolvido é similar em ambos os lugares, ou em que a mesma pessoa desempenha a mesma função em lugares e tempos diferentes. Se o caso correto for o último, então fica clara a circulação de pessoas entre essas povoações. Mais evidente e segura se torna a noção da ligação estreita

${ }^{39}$ Falamos de Constança Manuel, esposa do, então, infante D. Pedro, futuro D. Pedro I. Retomaremos esta senhora adiante.

${ }^{40}$ No documento de 1346 que já mencionámos (A.N.T.T., Ordem de Cister, Mosteiro de Santa Maria de Alcobaça, 2. incorporação, maço 56, n. ${ }^{\circ}$ 11), Lourenço Alvares é o juiz do lugar pela infanta D. Constança. Pouco tempo depois, um Lourenço Alvares é juiz pela mesma infanta na vila de Alenquer (A.N.T.T., Ordem de Cister, Mosteiro de Santa Maria de Alcobaça, 2. ${ }^{\mathrm{a}}$ incorporação, maço 62, n. ${ }^{\circ}$ 2).

Revista Vernáculo n. ${ }^{\circ} 43$ - primeiro semestre/2019

ISSN $2317-4021$ 
entre ambas quando verificamos que a infanta D. Constança recebeu Aldeia Galega em arras, embora isso não esteja expresso na respectiva carta de doação ${ }^{41}$. Aí, apenas surge a vila de Alenquer, mas é seguro que a infanta foi igualmente senhora de Aldeia Galega, uma vez que as autoridades da vila (juiz e tabelião, pelo menos) se apresentam como desempenhando o seu cargo em nome da infanta.

Não sabemos se o pelourinho de Aldeia Galega é testemunha destas mudanças, mas o facto é que na sua base se inscreve o ano de 1414, que pode perfeitamente estar ainda na era hispânica ${ }^{42}$, e ser, na era cristã, o ano de 1376 . É muito provável que a base não corresponda à coluna deste pelourinho ${ }^{43}$. Esta é tida como manuelina, e, portanto, não datável em consonância com a inscrição. Essa coluna pode ter sido erguida por alturas da reforma dos forais executada por D. Manuel.

${ }^{41}$ Como dissemos na nota anterior, as autoridades identificam-se como da infanta D. Constança. Mas, nas suas arras, apenas se indicam as vilas de Montemor-o-Novo, Viseu e Alenquer. As arras da infanta estão transcritas em SOUSA, D. António Caetano de.Provas da História Genealógica da Casa Real Portuguesa. Lisboa Ocidental: Na Oficina Sylvania da Academia Real, 1739, p. 285. Tomo I.

${ }^{42}$ Até 1422, Portugal contou os anos pela era hispânica. Seguindo a documentação, escrita, a epigrafia terá feito a mudança pela mesma altura. A numeração romana predominou até c. 1475. Para uma análise cuidada da epigrafia medieval portuguesa, vide: BARROCA, Mário Jorge, Epigrafia Medieval Portuguesa. Lisboa: Fundação Calouste Gulbenkian, Fundação para a Ciência e a Tecnologia - Ministério da Ciência e da Tecnologia, 2000. 3 vols. Não deixa de ser um pouco exótica para o período a forma como é marcado o ano no pelourinho em causa: MCDXIV. Quanto às dezenas e às unidades, a contagem é progressivamente mais regressiva do que progressiva (ou seja, substitui-se, por exemplo, o VIIII por IX). Só um estudo direcionado à epigrafia a par das fontes escritas talvez possa justificar a diferença.

${ }^{43}$ Os dois degraus superiores atuais foram colocados em 1936. Através de uma fotografia do Arquivo Municipal de Lisboa é possível verificar que, antes da substituição, a base do pelourinho parecia não corresponder à coluna. Vide a referência infra, nota 45 .

Revista Vernáculo n. ${ }^{\circ} 43$ - primeiro semestre/2019

ISSN 2317-4021 
Aldeia Galega recebeu o seu foral novo em 1512. Na verdade, num inventário de bens da igreja local, datado de $1537^{44}$, uma das propriedades da Igreja é situada junto à vila, aos "Pelourinhos" ${ }^{45}$. O plural pode remeter-nos à existência de dois pelourinhos, o que faz sentido tendo em conta a discrepância entre data e estilo de construção que referimos acima. Porque razão existiriam dois em simultâneo, não sabemos, por agora, dizer. Mas é possível que, à luz de um registo fotográfico nosso contemporâneo, a coluna do pelourinho manuelino tenha sido colocada posteriormente sobre o pé de outro, anterior. ${ }^{46}$

De qualquer forma, se acreditarmos que a base do pelourinho mais antigo não foi movida, situar-se-ia nas imediações do antigo Paço do Concelho, referido pela primeira vez em $1351^{47}$. Não é impossível, claro, que o Paço existisse antes dessa data, e que a documentação nos falhe: em 1340, Afonso IV ordenara que em todos os concelhos os vereadores se encontrassem em local perfeitamente predefinido. ${ }^{48} \mathrm{~A}$

${ }^{44}$ Em cópia do século XIX conservou-se um Tombo de bens da Igreja Colegiada de Santa Maria de Aldeia Galega em 1537, que se encontra no Arquivo da Igreja Paroquial de Nossa Senhora dos Prazeres de Aldeia Galega da Merceana, sendo o Liv. N. ${ }^{\circ} 37$.

${ }^{45}$ Trata-se da parcela . $^{\circ} 8$.

${ }^{46}$ Arquivo Histórico da Câmara Municipal de Lisboa - Fotográfico ACU000900.

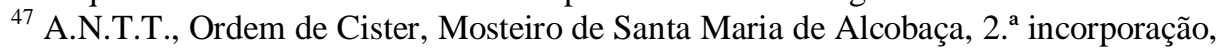
maço 50, n. ${ }^{\circ}$ 1362. O documento está em relativo mau estado, mas a referência é percetível. É o mesmo documento em que o tabelião se diz pela primeira vez de Aldeia Galega.

${ }^{48}$ Vide TRINDADE, Luís. Casas da Câmara ou Paços do Concelho: espaços e poder na cidade tardo-medieval portuguesa. In: RIBEIRO, Maria do Carmo e MELO, Arnaldo Sousa (coords.). Evolução da Paisagem Urbana. Sociedade e Economia. Braga: CITCEM - Centro de Investigação Transdisciplinar «Cultura, Espaço e Memória», Maio de 2012. pp. 209-227.

Revista Vernáculo n. ${ }^{\circ} 43$ - primeiro semestre/2019

ISSN 2317-4021 
primeira referência ao Paço do Concelho, é, perante isto, um pouco tardia, mas lógica. Ainda assim, só o conseguimos reencontrar após 1351 em documento copiado no Tombo de 1537 que referíamos há pouco. A 04.11.1412, perante os juízes da vila, Constança Gonçalves acerta com a Igreja de Santa Maria de Aldeia Galega, representada pelo prior Afonso Lourenço, o pagamento de um aniversário. ${ }^{49}$

Supomos que esse antigo Paço corresponde ao edifício situado atrás do Pelourinho, da perspetiva de quem o observa frente ao brasão do concelho, por uma fotografia anterior a 1936, em que se identifica a antiga Casa da Câmara. ${ }^{50}$ Com a devida ressalva de que o sítio possa ter oscilado, faz sentido que o Paço do Concelho se situasse naquela praça, e naquela posição: o lugar é pleno de carga simbólica. Na mesma praça, preenchendo praticamente todo o restante espaço, se situavam outros dois grandes símbolos de poder locais: a Casa da Rainha (atualmente sede da junta de freguesia), possivelmente um antigo paço régio ${ }^{51}$; e a igreja da Misericórdia, instalada no século XVI ou XVII. A única instituição com localização externa a este lugar é a própria Igreja Colegiada, mais acima na colina e só. Não é impossível que isso se possa justificar facilmente por uma questão de orografia ou até de

${ }^{49}$ É o $2{ }^{\text {o }}$ documento copiado.

${ }^{50} \mathrm{~A}$ legenda regista que o Pelourinho se situa junto à Antiga Casa da Câmara, ainda que identifique mal a localidade. Arquivo Histórico da Câmara Municipal de Lisboa Fotográfico ACU000900.

51 A existência do Paço foi identificada por GOMES, Rita Costa. The making of a court society. Nova. Iorque: CombrigdeUniversityPress, 2003, p. 334. (ed. Portuguesa: A Corte dos Reis de Portugal no final da Idade Média. Lisboa: Difel, 1995.) 
desenvolvimento urbano. Aí a inclinação do terreno é maior, por oposição à praça que se tornaria central e se encontra em zona mais plana. Não obstante, a torre da Igreja de Santa Maria pode ter sido um lugar de reunião e encontro da comunidade mais antigo, uma vez que assim é identificada pelo menos uma vez, em 1331: é junto a ela que se publica uma sentença de Afonso IV. ${ }^{52}$ Não seria estranho crer que a construção de um Pelourinho, e mais ainda do Paço, tenha feito mover o local de reunião da população da torre da igreja para a praça.

\section{Um problema de homonímia entre lugares}

Feito este percurso pela evolução dos topónimos "Montes de Alenquer" e "Aldeia Galega", em estreita proximidade com o desenvolvimento urbano e institucional do lugar, resta-nos apenas perceber porquê o acrescento "da Merceana". Mas para isso, precisamos de dar um passo atrás. Coexistiram com o alvo do nosso estudo, vagamente na região de Lisboa, pelo menos outras duas homônimas "Aldeia Galega": uma na freguesia de São João das Lampas, em Sintra, sendo a outra Aldeia Galega do Ribatejo ${ }^{53}$. A segunda, ribeirinha ao rio Tejo, fazia parte dos domínios da Ordem de Santiago, mas era referida amiúde, mais que não fosse pela proximidade a Lisboa. De facto,

52 A.N.T.T., Colegiada de Nossa Senhora dos Prazeres de Aldeia Galega da Merceana, n. ${ }^{\circ} 17$ (Numeração a azul, maço das Igrejas de Aldeia Galega e Reguengo Grande). Curiosamente, o tabelião ainda se diz dos Montes de Alenquer nesse documento. É a última vez que um tabelião se identifica apenas assim.

53 Assim se identifica, por exemplo, em: A.N.T.T., Cónegos Regulares de Santo Agostinho, Mosteiro de Chelas, maço 2, n. ${ }^{\circ} 28$.

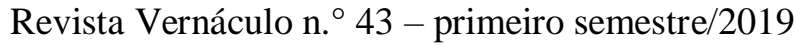

ISSN 2317-4021 
conhecemos a existência deste lugar desde cedo e com uma história algo análoga pela originalidade: numa área em que o concelho é dividido em dois polos que coexistem, essa Aldeia Galega é uma das povoações agrupadas em torno do polo que tem, à cabeça, a Igreja de Santa Maria de Sabonha. Em conjunto com o outro polo, em torno da Igreja de São Lourenço de Alhos Vedros, funcionava o Concelho do Ribatejo. $^{54}$

É natural que fosse preciso desfazer a confusão que podia existir quando se referia qualquer uma destas localidades... e assim, a chancelaria régia ${ }^{55}$ começou a aplicar a expressão "de apar da Merceana”, para designar a vila de Aldeia Galega. Que Merceana? Trata-se de uma aldeia próxima (cerca de $2 \mathrm{~km}$ ) de Aldeia Galega, que recolhe o nome, na tradição popular, da lenda do aparecimento de uma imagem da Virgem Maria, com Cristo morto no regaço ${ }^{56}$. O local foi

${ }^{54}$ A união desfazer-se-ia após a invasão castelhana no contexto das guerras que levaram o mestre de Avis ao trono, uma vez que se perdeu a documentação que permitia fazer funcionar aquele concelho. Dividiram-se então em dois municípios diferenciados. A propósito da formação de concelhos foi esta situação mencionada como estudo de caso em: SILVA, Manuela Santos e OLAIA, Inês. Bombarral e Aldeia Galega da Merceana: de montes agrícolas a sedes de concelho. Comunicação apresentada no Colóquio Pequenas Cidades: um objeto de estudo coerente?, 1 . $^{\circ}$ Colóquio da International Network - Small Cities in Time, Castelo de Vide, 4 de outubro de 2017.

${ }^{55}$ Tanto quanto apurámos, data do início do governo de D. João I a primeira referência a Aldeia Galega já com o denominativo "d'a par da Merceana" nas Chancelarias Régias. O documento está transcrito com o número 728 em DIAS, João José Alves (ed.). Chancelarias Portuguesas: D. João I.Revisão de A. H. de Oliveira Marques, transcrições de Pedro Pinto e José Jorge David de Freitas. Lisboa: Centro De Estudos Históricos da Universidade Nova De Lisboa, 2004-2006. Volume I. Parte 2.

${ }^{56}$ A tradição conservou que a imagem de Nossa Senhora da Piedade, venerada no Santuário dessa invocação na Merceana, foi encontrada por um pastor a quem todos os

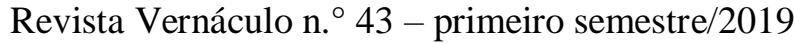

ISSN $2317-4021$ 
um centro de peregrinação de dimensão razoável $^{57}$ e, provavelmente, serviria perfeitamente o fito de distinguir as Aldeias Galegas. Não sabemos de onde vem este topónimo, mas uma coisa é certa: está ligado de alguma forma à existência desse Santuário.No início do século XV temos notícia de Santa Maria Merceana, como igreja sufragânea de Santa Maria de Aldeia Galega ${ }^{58}$, da mesma maneira que o regente D. Pedro, em nome de Afonso V, concede proteção a "Nossa Senhora Santa Maria Merceana"59.

Facto igualmente curioso é que a documentação produzida in loco até muito tarde ignora o "de a par da Merceana": tabeliães e documentação de instituições religiosas mantêm a designação do local

dias faltava um boi. Quando teria ido averiguar onde andava o animal, que se chamava Marciano, encontrou a imagem, aos pés da qual se achava o boi ajoelhado. O lugar onde a igreja foi erguida, que não corresponderia ao local original do "achamento" da imagem, ficou então com o nome de Merceana, por ter derivado do nome do boi.

${ }^{57}$ No século XV, pelo menos, recebia um conjunto de peregrinos razoável que parece ter sido impedido de lá chegar em 1431 por medo de contágio de uma peste. FIGUEIREDO, Paula. Igreja de Nossa Senhora da Piedade da Merceana / Santuário de Nossa Senhora da Piedade da Merceana. SIPA - Sistema de Informação Para o Património Arquitetónico. Sacavém: Direção-Geral do Património Cultural, 2014. Disponível em: <http://www.monumentos.gov.pt/site/app_pagesuser/SIPA.aspx?id=6246>

${ }^{58}$ A 15.05.1404, o prior de Santa Maria de Aldeia Galega apresenta-se perante os juízes de Aldeia Galega para fazer cumprir o testamento de Vicente Anes. Este último mandava ser sepultado no adro de Santa Maria Merceana, junto com o filho que lá se encontrava, fazendo doação a essa igreja. Por ser sufragânea de Aldeia Galega é o prior desta última que se apresenta perante os juízes. O documento está trasladado no tombo de 1537 que já referimos, sendo o $100^{\circ}$ instrumento copiado.

59 "Aa ygreia de nossa señora santa maria merçeana e a noue moradores que viuerem darredor della priuilegio per que os elRey tomou em sua guarda e emcomenda e mais etc." A.N.T.T., Leitura Nova, Liv. 26, fls. 60r-60v.

Revista Vernáculo n. ${ }^{\circ} 43$ - primeiro semestre/2019

ISSN 2317-4021 
apenas como "Aldeia Galega"60. Afinal, não há outra dentro do espaço em que desempenham as suas funções de que seja preciso distingui-la. Só no período moderno se vê aparecer na documentação local a designação completa e imposta de fora para dentro ${ }^{61}$; da mesma maneira que, ainda hoje, perdura a disparidade para a maioria dos habitantes. Curiosamente, o Numeramento de 1527 não identifica Aldeia Galega com o "de a par da Merceana”: terá sido porque não havia outra Aldeia Galega, naquele contexto, de que houvesse necessidade de distinguir esta? Mesmo que se considere a totalidade do Numeramento para todas as divisões administrativas (comarcas), nenhuma outra Aldeia Galega é arrolada. Sendo esta a única vila régia e mais ainda, da Rainha - com este nome (Aldeia Galega de S. João das Lampas não é cabeça de Concelho; Aldeia Galega do Ribatejo não é contada na Comarca de Entre Tejo e Guadiana, mas sim entre as vilas do mestrado da Ordem de Avis, de que não possuímos o arrolamento), é possível. Pode ser que, por outro lado, ser produzido no lugar, sob

${ }^{60}$ Não recolhemos, até ao momento, traços seguros da utilização dessa expressão em documentação medieval produzida em Aldeia Galega.

${ }^{61}$ Não tivemos oportunidade de estudar o período em pormenor, mas o Tombo de 1537 abre assim: "Anno do nascijmento de Noso Senhor Jesus Christo de mil e quinhentos e trinta e sete anos aos quatro dias do mes d'Agosto na villa d'Alda Gualegua d'apar da Merciana". É o primeiro caso de que temos notícia em que um documento produzido na vila assume a expressão "d'apar de" para designar a localidade. Não é impossível que haja referências anteriores, mas são, quando muito, esporádicas e, talvez resultado de pessoas externas àquele espaço (pode ser o caso de A.N.T.T., Ordem de Cister, Mosteiro de Santa Maria de Lorvão, Gaveta 6, maço 2, n. ${ }^{\circ}$ 20/2).

Revista Vernáculo n. ${ }^{\circ} 43$ - primeiro semestre/2019

ISSN 2317-4021 
instruções dos homens-bons do concelho ${ }^{62}$, tenha sido uma opção deliberada a escolha da forma com que o nome do lugar é apresentado. Tal como acontece ainda hoje: uma obra produzida em 2002, no Concelho de Alenquer, sobre as suas freguesias, nunca identifica Aldeia Galega como "Aldeia Galega da Merceana": nem a freguesia, nem o lugar. ${ }^{63}$

\section{A conclusão possível}

Em suma, podemos concluir que a evolução da toponímia desta região é um espelho da evolução histórica da mesma: de uma área mal definida, mal povoada, emergiu uma comunidade de colonos organizada, que conquistou o reconhecimento externo. Foi a sua "normalização", isto é, a sua adequação às características comuns a outras unidades administrativas, que ditou o fim da sua originalidade e o desaparecimento do próprio topónimo com que se identificava. Assim sintetizado, o processo parece curto e indolor. Na verdade, não terá sido muito longo, quando comparado com o largo tempo da história: cerca de século e meio a dois séculos.

Essa comunidade "estrangeira", na falta de vocábulo mais preciso com que a definir, terá chegado e iniciado o seu desenvolvimento algures durante a segunda metade do século XII. Nos alvores do século

${ }^{62}$ COELHO, António Borges. Na Esfera do Mundo. Lisboa: Editorial Presença, 2013, p. 113.

${ }^{63}$ Estamos a reportar-nos a MELO, António de Oliveira, GUAPO, António Rodrigues e MARTINS, José Eduardo. "Freguesia de Aldeia Galega", op. Cit., pp. 31-56.

Revista Vernáculo n. ${ }^{\circ} 43$ - primeiro semestre/2019

ISSN 2317-4021 
XIII era já suficientemente organizada para ter, pelo menos, uma paróquia atribuída, e se ver isentada de impostos; em meados do século apresenta-se encabeçada por um juiz e com símbolos próprios, e vive assim até aos alvores do século XIV. Em 1305 tem poder suficiente para negociar a sua carta de foral, comprá-la, como a própria documentação refere, navegando os meandros da corte para chegar a D. Dinis. Em meados do século sofre uma mutação tão indelével quanto invisível na documentação: é possível que se tenham construído os símbolos físicos de um concelho (o pelourinho e o Paço) e que a designação primeva tenha caído, em favor do nome do lugar que servia de cabeça ao concelho. Simultaneamente, a queda da designação fez com que, no final do século, fosse necessário encontrar forma de distinguir o lugar de outros seus homónimos, para quem olha de fora.

Assim, passamos do Concelho dos Montes de Alenquer, para a vila e termo de Aldeia Galega e depois para a vila e termo de Aldeia Galega de a par da Merceana. Os sintomas da transformação do topónimo vivem até hoje: quem olha de dentro o lugar identifica-o tendencialmente sem precisar de expressar o "de a par", mas a unidade administrativa, a freguesia contemporânea, é "Aldeia Galega da Merceana", contraindo a expressão original "de a par" em apenas "da".

Muito do que aqui dissemos é uma questão de identidade, e essa identidade parece estar perfeitamente definida muito cedo neste caso, corria o século XIII: não só porque há um selo, que representa aquele grupo, mas porque há uma autoridade local que se respeita, da mesma 
forma que um nome designa aquele local, se solidifica na memória e na tradição e persiste ao longo dos séculos. Mesmo que essa memória o desvie do sentido original, ela mostra como foi forte aquela presença. É, igualmente, para resgatar a memória que a História pode servir. Parecenos que é precisamente esse o caminho que estamos a trilhar. ${ }^{64}$

\section{Referências}

\section{Fontes}

Fontes iconográficas

Arquivo Histórica da Câmara Municipal de Lisboa AML/FOTOGRÁFICO ACU000900, disponível em http://goo.gl/fauTn4

\section{Fontes Manuscritas}

\section{Arquivo Nacional Torre do Tombo}

Chancelarias Régias

Chancelaria de D. Dinis, liv. 3.

Colegiadas

Colegiada de Nossa Senhora da Várzea de Alenquer, n. ${ }^{\circ} 23$.

Colegiada de Nossa Senhora dos Prazeres de Aldeia Galega da Merceana

Igrejas de Aldeia Galega da Merceana e Reguengo Grande, N. ${ }^{\text {os }} 14$ a 28 (com a numeração a azul).

Colegiada de São Pedro de Torres Vedras

$$
\text { Maço 1, n.. }{ }^{\text {s }} 16,64,69 \text { e } 70
$$

${ }^{64}$ Ao fechar esta breve reflexão, importa-nos agradecer à Prof. Doutora Manuela Santos Silva. Esta abordagem não seria a mesma se não tivesse beneficiado das muitas ideias trocadas em torno dos Montes de Alenquer.

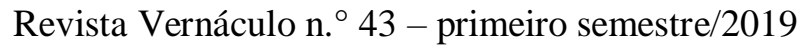

ISSN 2317-4021 
Gavetas

Gaveta 13, maço 9, n. 49

Gaveta 15,

Maço 22, n. ${ }^{\circ} 22$

Maço 23, n. 3 .

Leitura Nova,Livro 26, fl. 60r-60v.

Mosteiros

Cónegos Regulares de Santo Agostinho,

Mosteiro de Chelas, maço 2, n. 28.

Mosteiro de Santa Cruz de Coimbra, Liv. 94, fl. 153v-154r; Liv. 6, fl. $3 r$.

Ordem de Cister,

Mosteiro de Santa Maria de Alcobaça, 2. ${ }^{a}$ incorporação, maço 50, n. ${ }^{\circ}$ 1362; maço 56, n. ${ }^{\circ} 11 ;$ maço $62, \quad$ n. ${ }^{\circ}$. Mosteiro de Santa Maria de Celas, maço 9, n. 31 Mosteiro de Santa Maria de Lorvão, Gaveta 6, maço 2, n. ${ }^{\circ}$ 20/2 Mosteiro de Santos-o-Novo,

n. ${ }^{\circ}$

n. ${ }^{\circ} 1556$

Arquivo Histórico da Igreja Paroquial de Nossa Senhora dos Prazeres de Aldeia Galega da Merceana

Livro 37 - Inventários dos bens da Igreja no ano de 1537

\section{Archivo-Biblioteca de la Catedral de Santiago}

ACS, Actas Capitulares v. I, f $\mathrm{f}^{\mathrm{1}}$ 138v-139r

ACS, Carpeta Documentos Sueltos 14, $\mathrm{n}^{\circ} 38$

ACS, Carpeta Documentos Sueltos 15, no 74

ACS, Carpeta Documentos Sueltos 19, no 32, 33, 34, 35, 36 e 37

ACS, Tumbo E, f. $70 \mathrm{r}-71 \mathrm{v}$

ACS, Tumbo E, f. ${ }^{\circ} 107 \mathrm{v}-110 \mathrm{v}$

ACS, Tumbo F, f. $5 \mathrm{v}$.

ACS, Tumbo de Tenencias 3 , f. ${ }^{\circ} 9 \mathrm{v}$ 


\section{Archivo Historico Universidad de Santiago}

CLERO, Colección Blanco Cicerón, Carpeta 137, № 51

Fontes impressas

AZEVEDO, Rui de e ALMEIDA, Luís Ferrand de. Documentos medievais portugueses. Lisboa: Academia Portuguesa de História, 1941. Vol. 1, tomo 2.

AZEVEDO, Rui Pinto de; COSTA, Avelino de Jesus da; PEREIRA, Marcelino.Documentos de D. Sancho I. Coimbra: Centro de História da Sociedade e da Cultura da Universidade de Coimbra, 1979. pp. 180181. Vol. 1

BAPTISTA, João Maria. Aldeia Gallega da Merciana. In: Chorographia Moderna do Reino de Portugal. Lisboa: Typographia da Academia Real das Sciencias, 1876. pp. 356-357.vol. IV.

BOISSELLIER, Stéphane. La Construction administrative d'un royaume: registres de bénefices ecclésiastiques portugais: XIII-XIVe siècles. Lisboa: Universidade Católica Portuguesa, Centro de Estudos de História Religiosa, 2012. pp. 57-103.

COSTA, António Carvalho da. Capítulo II: Da Villa de Aldea Galega da Merciana. Corografia Portugueza e DescripçamTopografica do Famoso reyno de Portugal com as notícias das fundaçoens das cidades, villas e Lugares, que contem Varoens ilustres, Genealogias das Familias nobres, fundaçoens de Conventos, Catalogos dos Bispos, antiguidades, maravilhas da natureza, edifícios e outras curiosas obervaçoens. Lisboa: na oficina de Valentim da Costa Deslandes, 1712. pp. 81-82. Tomo Terceiro.

DIAS, João José Alves (ed.).Chancelarias Portuguesas: D. João I.Revisão de A.H. de Oliveira Marques, transcrições de Pedro Pinto e José Jorge David de Freitas. Lisboa: Centro DeEstudos Históricos da Universidade Nova De Lisboa, 2004-2006. Volume I. Parte 2.

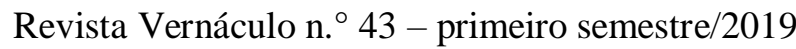

ISSN $2317-4021$ 
FREIRE, Anselmo Braamcap. Povoacao da Estermadura no XVI. seculo. Archivo Historico Portuguez, Lisboa, Vol.nº, n. ${ }^{\circ}$ 7, pp. 241284, 1908.

HENRIQUES (da Carnota), Guilherme João Carlos. Alenquer e seu Concelho. Fac-símile da edição de 1873. Arruda dos Vinhos: Arruda Editora, 2005. p. 302.

LEAL, Pinho. Aldeia Gallega da Merciana. Portugal Antigo $e$ Moderno. Lisboa: Livraria Editora de Mattos Moderira e Companhia, 1873. pp. 82-85. VolI

MELO, António de Oliveira, GUAPO, António Rodrigues e MARTINS, José Eduardo, O Concelho de Alenquer: subsídios para um roteiro de arte e etnografia. [Alenquer]: Câmara Municipal de Alenquer e Associação para o Estudo e Defesa do Património de Alenquer, 2002. pp. 31-56. Vol. 1

O Livro das Lezírias d'El-Rei D. Dinis. Transcrição, Estudo Introdutório e Notas de Bernardo de Sá Nogueira. Lisboa: Centro de História, 2003. pp. 97-101.

RÊPAS, Luís Miguel. Quando a Nobreza Traja de Branco - a comunidade cisterciense de Arouca durante o abadessado de D. Luca Rodrigues (1286-1299).Leiria: Magno Edições, 2003. pp. 458-459.

RÊPAS, Luís Miguel. Margarida Anes Fafes de Lanhoso (1272-1316). A mulher, a religiosa, a gestora.RevistaPortuguesa de História, Coimbra,t. 34, pp. 491-533, 2000.

SÁNCHEZ SÁNCHEZ, Xosé Manuel. El Tumbo D de la Catedral de Santiago: catalogación y regesta. Annuarium Sancti Iacob, Santiago de Compostela, No. 4, pp. 27-106, 2015.

SÁNCHEZ SÁNCHEZ, Xosé Manuel, El tumbo E de la Catedral de Santiago: catalogación y regesta. Annuarium Sancti Iacobi, Santiago de Compostela, $N^{\circ} .5$, pp. 21-123, 2016.

Revista Vernáculo n. ${ }^{\circ} 43$ - primeiro semestre/2019

ISSN 2317-4021 
SOUSA, D. António Caetano de, Provas da História Genealógica da Casa Real Portuguesa, Lisboa Ocidental, Na Oficina Sylvania da Academia Real, 1739. p. 285. (Provas da História Genealógica da Casa Real Portuguesa, Tomo I)

VIANA Y VIEITES, José Inacio Fernandez de; GONZÁLEZ BALASCH, Maria Teresa. Documentos sobre derechos y posesiones de la iglesia compostelana en tierras portuguesas en los tumbos "b" y "c" y en el "tumbillo de concordias" de la Catedral de Santiago. Cuadernos de estudios medievales y ciencias y técnicas historiográficas, Granada, no. 17, pp. 359-398, 1992.

\section{Bibliografia}

BARBOSA, Pedro Gomes.Povoamento e estrutura agrícola na Estremadura Central:séc. XII-1325.Lisboa: I.N.I.C., 1992.

BARROCA, Mário Jorge, Epigrafia Medieval Portuguesa. Lisboa: Fundação Calouste Gulbenkian, Fundação para a

Ciência e a Tecnologia - Ministério da Ciência e da Tecnologia, 2000. 3 vols.

COELHO, António Borges. Na Esfera do Mundo. Lisboa: Editorial Presença, 2013.

DIRECÇÃO GERAL DO PATRIMÓNIO CULTURAL. Pelourinho de Aldeia Galega da Merceana.Património Cultural, [Lisboa]:s.d.. Disponível em <www.patrimoniocultural.gov.pt/pt/patrimonio/patrimonio-imovel/pesquisado-patrimonio/classificado-ou-em-vias-de-classificacao/geral/view/70505 > Acesso em: 14.12.17.

FERNANDES, Hermenegildo. D. Sancho II: tragédia. Lisboa: Círculo de Leitores, 2006.

FIGUEIREDO, Paula. Igreja de Nossa Senhora da Piedade da Merceana / Santuário de Nossa Senhorada Piedade da Merceana. , SIPA - Sistema de Informação Para o Património Arquitetónico. Sacavém: Direção-Geral do Património Cultural, 2014. Disponível em <http://www.monumentos.gov.pt/site/app_pagesuser/SIPA.aspx?id=6246>

Revista Vernáculo n. ${ }^{\circ} 43$ - primeiro semestre/2019

ISSN 2317-4021 
FERRO, João Pedro. Alenquer Medieval (séculos XII-XV): subsídios para o seu estudo. Cascais: Patrimonia, 1996.

FIGANIÈRE, Frederico Francisco de La. Memorias das Rainhas de Portugal. D. Teresa - Santa Isabel. Lisboa: Typographia Universal, 1859.

GOMES, Rita Costa. The making of a court society. Nova. Iorque: CombrigdeUniversityPress, 2003.

MATTOSO, José. Identificação de um país. Lisboa: Círculo de Leitores, 2015.

MELO, António de Oliveira; GUAPO, António Rodrigues; MARTINS, José Eduardo. Igreja de Nossa Senhora da Piedade - Merceana. In:

Concelho de Alenquer: subsídios para um roteiro de arte e etnografia. [Alenquer]: Câmara Municipal de Alenquer e Associação para o Estudo e Defesa do Património de Alenquer, 2002, pp. 36-39.Vol. 1

SILVA, Carlos Guardado da. "A toponímia e o povoamento Árabe e Moçárabe na «região» de Torres Vedras”, In: . (coord.) Turres Veteras I. Actas de História Medieval. Torres Vedras: Câmara Municipal de Torres Vedras, 2000, pp. 29-36.

NUNES, Graça Soares; SILVA, Paulo (coord.).800 anos do foral 12122012.Vila Francade Xira: Museu Municipal, Câmara Municipal de Vila Franca de Xira, 2012.

OLIVEIRA-LEITÃO, André de. O Povoamento no Baixo Vale do Tejo: entre a territorialização e a militarização (meados do século IX - início do século XIV). 2011. 177 f. Dissertação (Mestrado em História Medieval) - Faculdade de Letras, Universidade de Lisboa, Lisboa.

REIS, António Matos. História dos Municípios. [S.1.]: Livros Horizonte, 2007. . Origens dos municípios portugueses. [Lisboa]: Livros Horizonte, 2002. 
RODRIGUES, Ana Maria Seabra de Almeida.Torres Vedras. A vila e o termo nos finais da Idade Média. Lisboa: Fundação Calouste Gulbenkian, Junta Nacional de InvestigaçãoCientífica, 1995.

SILVA, Manuela Santos. Galegos e Minhotos à conquista do litoral do centro de Portugal. Vestígios da sua presença e acção na região medieval de Óbidos. In: BARROCA, Mário Jorge (coord.). Carlos Alberto Ferreira de Almeida: in memoriam, [Porto], Faculdade de Letras da Universidade do Porto, 1999. pp. 397-408. Vol. II

SILVA, Manuela Santos e OLAIA, Inês. Bombarral e Aldeia Galega da Merceana: de montes agrícolas a sedes de concelho. Comunicação apresentada no Colóquio Pequenas Cidades: um objeto de estudo coerente?, $1 .^{\circ}$ Colóquio da International Network - SmallCities in Time, Castelo de Vide, 4 de outubro de 2017.

TRINDADE, Luís. Casas da Câmara ou Paços do Concelho: espaços e poder na cidade tardo-medieval portuguesa. In:

RIBEIRO, Maria do Carmo e MELO, Arnaldo Sousa (coords.), Evolução da Paisagem Urbana. Sociedade e Economia. Braga: CITCEM - Centro de Investigação Transdisciplinar «Cultura, Espaço e Memória», Maio de 2012, pp. 209-227.

VICENTE, António Balcão. et. al., O foral Medieval da vila de Torres Vedras. 15 de Agosto de 1250. Torres Vedras: Município de Torres Vedras, 2001.

Recebido em 20/08/18 aceito para publicação em 05/01/19

Revista Vernáculo n. ${ }^{\circ} 43$ - primeiro semestre/2019

ISSN $2317-4021$ 